\title{
A New Occupational Heat Tolerance Test: A Feasibility Study
}

Emily R Watkins BSc ${ }^{1} *$, Jemma Gibbons BSc, Yanoula Dellas BSc, Mark Hayes BSc $\mathrm{PhD}^{2}$, Peter Watt BSc $\mathrm{PhD}^{3}$, Alan Richardson $\mathrm{BSc} \mathrm{PhD}^{4}$

Environmental Extremes Laboratory, University of Brighton, Welkin Laboratories, Eastbourne, UK. BN20 7SN

*Corresponding author. E.R.Watkins@ brighton.ac.uk

\section{ABSTRACT}

Heat tolerance tests identify those susceptible to heat illnesses and monitor heat adaptations.

Currently, tolerance tests do not replicate the uncompensable heat strain environments experienced in some occupations. In addition, tests can take up to 2 hours to complete, and cannot offer intra and inter individual comparisons, due to the use of a fixed exercise intensity. This study aimed to assess the validity and reliability of a new heat occupational tolerance test (HOTT: $40 \mathrm{~min}$ at $6 \mathrm{~W} \cdot \mathrm{kg}^{-1}$ metabolic heat production, $50^{\circ} \mathrm{C} 10 \% \mathrm{RH}$, in protective clothing) to the standard heat tolerance test (HTT: $2 \mathrm{hr}$ walk at $5 \mathrm{~km} \cdot \mathrm{hr}^{-1} 1 \%$ gradient, $40^{\circ} \mathrm{C} 40 \% \mathrm{RH}$, in shorts and t-shirt). Eighteen participants (age: $21 \pm 3$ yrs, body mass: $81.3 \pm 5.9 \mathrm{~kg}$ ) completed trials to assess the validity and/or reliability of the HOTT. Peak rectal temperature $\left(\mathrm{T}_{\mathrm{re}}\right)$ displayed strong agreement and low measurement error $\left(0.19^{\circ} \mathrm{C}\right)$ between HTT $\left(38.7 \pm 0.4^{\circ} \mathrm{C}\right)$ and HOTT $\left(38.6 \pm 0.4^{\circ} \mathrm{C}\right)$. Strong agreement was also displayed for physiological and perceptual measures between the two HOTT trials, including peak $\mathrm{T}_{\mathrm{re}}\left(38.5 \pm 0.4^{\circ} \mathrm{C}\right.$

\footnotetext{
${ }^{1}$ Emily R Watkins

0000-0001-8342-7373

${ }^{2}$ Mark Hayes

$0000-0002-1507-3750$

${ }^{3}$ Peter Watt

$0000-0002-8261-6022$

${ }^{4}$ Alan Richardson

0000-0001-8931-2518
} 


\section{ACCEPTED MANUSCRIPT}

vs. $\left.38.5 \pm 0.4^{\circ} \mathrm{C}\right)$ and peak heart rate $\left(182 \pm 20\right.$ b. $\min ^{-1}$ vs. $182 \pm 21$ b.min $\left.{ }^{-1}\right)$. The HOTT is the first tolerance test that assesses individuals' responses whilst wearing protective clothing in high temperatures. It can consistently identify individuals' levels of heat tolerance within a reduced time frame. In addition, it allows for participant monitoring over time and comparisons between individuals to be made. A continuum based approach is recommended when assessing individuals' responses to the HOTT.

\section{Keywords:}

Heat tolerance; Occupational health; Validity; Reliability; Personal Protective Equipment

\section{Abbreviations:}

CV, Coefficient of variation; HTT, Heat tolerance test; HOTT, Heat occupational tolerance test; ICC, Intra-class correlation coefficient; LOA, Limits of agreement; TEM, Typical error of the measurement 


\section{ACCEPTED MANUSCRIPT}

\section{INTRODUCTION}

Individuals who wear personal protective clothing in hot environments, for example firefighters and the military, can experience uncompensable heat stress scenarios, whereby heat is gained from both the environment and muscular contractions, but heat dissipation is limited (Brotherhood 2008). In these situations the cardiovascular system responds by redistributing blood flow to the cutaneous circulation, in an attempt to increase convective and evaporative heat loss (Selkirk et al. 2001). However, the reduced capacity to dissipate heat via evaporation results in the body storing heat and core temperature rising. This can lead to an increase in fatigue and possibly heat exhaustion in some individuals (Hargreaves 2008). Heat illnesses can vary from heat cramps to heat stroke with syncope and dizziness common, which will inevitably require time off work to recover, and can be fatal if not treated immediately (Binkley et al. 2002). Some individuals are at a greater risk of suffering from a heat illness than others, due to an increased sensitivity to heat (Selkirk et al. 2001; Kenny et al. 2010).

Body composition, specifically the proportion of body fat, and aerobic fitness have both been suggested to effect heat tolerance. Individuals with a higher percentage of body fat have a lower body

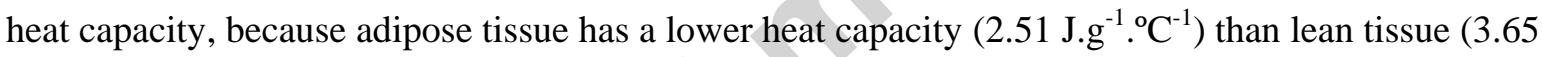
$\left.\mathrm{J} \mathrm{g}^{-1} \cdot{ }^{\circ} \mathrm{C}^{-1}\right)$, and consequently will experience a faster rate of increase in core temperature at a set heat storage (Selkirk et al. 2001). Individuals with a lower level of aerobic fitness, identified via maximal oxygen uptake ( $\mathrm{V}_{2}$ max), may also be less tolerant during exercise in the heat (Lisman et al. 2014). Aerobic training lowers the core temperature threshold that sweating and vasodilation are initiated at, enhancing heat dissipation (Cheung et al. 2000). However, during an uncompensable heat stress situation this may not provide any additional benefit, and could instead potentiate the rate of dehydration (Cheung et al. 2000).

Recent findings suggest that when exercise is set at a fixed percentage of $\dot{V}_{2}$ max, metabolic heat production $\left(\dot{\mathrm{H}}_{\text {prod }}\right)$ has the greatest impact on heat tolerance, explaining $\sim 50 \%$ of variation, with body fat only having a small impact $(2.3 \%)$ and $\dot{\mathrm{V}}_{2}$ max having no impact on change in core temperature (Cramer et al. 2015). When $\dot{\mathrm{H}}_{\text {prod }}$ is controlled for, body fat percentage has been noted to elicit a $2.2^{\circ} \mathrm{C}$ 


\section{ACCEPTED MANUSCRIPT}

higher core temperature in the high adiposity group, indicating that body fat variations do influence an individual's heat tolerance (Dervis et al. 2015). When comparing individuals of different body mass, it is now recommended that the exercise intensity is set at a fixed metabolic heat production in watts per kilogram, rather than at a fixed percentage of $\dot{\mathrm{V}}_{2}$ max, to prevent systematic variations in core temperature (Jay et al. 2011; Cramer and Jay 2014).

Due to the multi-faceted nature of heat tolerance, it is difficult to predict how individuals will respond from predisposing factors alone. A heat tolerance test (HTT) is therefore needed to successfully identify individuals who may be at a higher risk of a heat illness. A HTT can also be used to recommend when individuals can return to work post illness, and establish if an individual has become acclimatised to heat exposure, and is therefore better able to cope with the environment (Moran et al. 2007). HTT have been used within the military and with athletes for these reasons for many years.

The HTT most commonly used within occupational settings was developed for the Israeli Defence Force to evaluate military personnel's heat tolerance (Moran et al. 2004; Moran et al. 2007). The HTT involves a 2 hour walk in $40^{\circ} \mathrm{C}$ and $40 \% \mathrm{RH}$ at $5 \mathrm{~km} \cdot \mathrm{h}^{-1}$ with a $2 \%$ gradient (Moran et al. 2007). According to the guidelines from Moran et al (2007), individuals with a rectal temperature $\left(\mathrm{T}_{\mathrm{re}}\right)$ exceeding $38.5^{\circ} \mathrm{C}$ or a heart rate (HR) exceeding $145 \mathrm{~b} \cdot \mathrm{min}^{-1}$ should be classified as heat intolerant. Tolerant individuals are expected to have a $\mathrm{T}_{\mathrm{re}}$ of $38.0 \pm 0.3^{\circ} \mathrm{C}$ and HR of $120 \pm 15 \mathrm{~b} \cdot \mathrm{min}^{-1}$. They are also expected to display a plateau in core temperature (Moran et al. 2004), with a difference of greater than $0.45^{\circ} \mathrm{C}$ in the last $60 \mathrm{~min}$ of the test suggested to distinguish heat intolerance in cases where $\mathrm{T}_{\mathrm{re}}$ and HR provide borderline responses (Amit et al. 2013). The further an individual deviates from the heat tolerant classification, the more pronounced their heat intolerance is. The HTT offers good construct validity, successfully distinguishing those who are heat tolerant from those who are not (Moran et al. 2007). Although, research does suggest that the use of a continuum to interpret heat tolerance, rather than dichotomous groupings, may better reflect the range and progression of individual responses (Taylor and Cotter 2006; Mee et al. 2015a). 


\section{ACCEPTED MANUSCRIPT}

This HTT offers little ecological validity when wearing protective clothing. During the $2 \mathrm{hr}$ test individuals exercise in shorts and t-shirts, allowing heat dissipation via evaporation to occur. This compensable heat stress environment is therefore different to that experienced with protective clothing. In addition, the use of a set exercise intensity, rather than a set metabolic heat production, may result in wide variations in core temperature responses and prevent comparisons between individuals being made. It is also likely that individuals such as firefighters will not be exposed to high temperatures for $2 \mathrm{hr}$, as they are limited to the volume of gas available in their self-contained breathing apparatus, often lasting up to 40min (Eglin 2007). To accurately assess heat tolerance in relation to occupational function, a new occupational HTT was designed to more closely replicate the type of heat exposure experienced.

This study aims to assess the validity of the new heat occupational tolerance test (HOTT) in comparison to the HTT, and also evaluate the reliability of the HOTT. It was hypothesised that 1) core temperature responses would be similar between the HTT and HOTT and 2) that physiological and perceptual responses would be similar at the end of both HOTT trials

\section{METHOD}

\subsection{Participants}

Eighteen male participants were recruited (age: $21 \pm 3$ yrs, body mass: $81.3 \pm 5.9 \mathrm{~kg}$, height: $180.0 \pm$ $6.5 \mathrm{~cm}$ ) from the University of Brighton. Participants were given the option to select if they wished to be involved with the validity or reliability testing, with some individuals opting to complete both. Seventeen participants (age: $21 \pm 3$ yrs, body mass: $81.7 \pm 5.9 \mathrm{~kg}$, height: $180.2 \pm 6.6 \mathrm{~cm}$ ) completed the validity trials and eleven participants (age: $21 \pm 2$ yrs, body mass: $80.5 \pm 5.6 \mathrm{~kg}$, height: $178.5 \pm$ $6.3 \mathrm{~cm}$ ) completed the reliability trials. Participants were required to provide informed written consent and complete a medical questionnaire prior to taking part in the study. The study was approved by the University of Brighton Ethics Committee and was in line with the Declaration of Helsinki (2013).

Participants were requested to avoid alcohol, caffeine, heat exposure $>25^{\circ} \mathrm{C}$, and exhaustive exercise 24 hours prior to taking part, with adherence checked via a questionnaire. 


\section{ACCEPTED MANUSCRIPT}

\subsection{Experimental Design}

Testing sessions followed a randomised cross over design. Participants were asked to complete two HOTT for the reliability sessions, and a HOTT and HTT for the validity sessions. Those involved in both the validity and reliability parts of this study were only required to complete 2 HOTT in total. Prior to their first session participants visited the laboratories to try on PPE, select sizes, and ensure they felt comfortable in the clothing. All trials were separated by a minimum of 5 days, to prevent heat adaptations, and were conducted in the morning beginning between 7:00am and 9:00am to control for circadian rhythms (Drust et al. 2005). Participants were also requested not to be exposed to heat $>25^{\circ} \mathrm{C}$ in the intervening days (Périard et al. 2015). Trials were completed during UK Autumn and Winter months (October - February).

\subsection{HOTT}

Each HOTT trial began with a $10 \mathrm{~min}$ rest period $\left(23.3 \pm 1.6^{\circ} \mathrm{C}, 34 \pm 11 \% \mathrm{RH}\right)$ whilst wearing fire protective clothing weighing $7.5 \mathrm{~kg}$ in total (boiler suit, trousers [Ballyclare Special Products Ltd.], jacket [Ballyclare Special Products Ltd.], boots [9005 GA, Jolly Scarpe, USA], fire hood [MSA Gallet, Bellshill, UK], helmet [F1SF, MSA Gallet, Bellshill, UK], and gloves [Firemaster 3, Southcombe Brothers Ltd, Somerset, UK]). Participants then entered the heat chamber $\left(50.0 \pm 1.1^{\circ} \mathrm{C}\right.$, $13 \pm 2 \% \mathrm{RH})$ where they walked continuously for $40 \mathrm{~min}$. During the first $15 \mathrm{~min}$ speed was altered every $5 \mathrm{~min}$ (starting from $4.5 \mathrm{~km} \cdot \mathrm{h}^{-1}$ ) to identify the correct speed needed for the participant to be working at a metabolic heat production of $6 \mathrm{~W} \cdot \mathrm{kg}^{-1}$. Speed was then maintained throughout with only small adjustments of $0.2 \mathrm{~km} \cdot \mathrm{h}^{-1}$ made when necessary to maintain the desired heat production. This process of speed adjustment occurred in both HOTT sessions, although the maximum speed difference that occurred between trials was $0.2 \mathrm{~km} \cdot \mathrm{h}^{-1}$. A metabolic heat production of $6 \mathrm{~W} \cdot \mathrm{kg}^{-1}$ was selected as pilot testing identified that this workload was the greatest reached by individuals at the end of the HTT.

\subsection{HTT}




\section{ACCEPTED MANUSCRIPT}

During the HTT trials participants rested for $10 \min \left(22.2 \pm 2.0^{\circ} \mathrm{C}, 31 \pm 5 \mathrm{RH}\right)$ whilst wearing their own shorts, cotton t-shirt and trainers. They then entered the heat chamber $\left(40.2 \pm 0.2^{\circ} \mathrm{C}, 40.7 \pm 1 \%\right.$ RH) and completed a $120 \mathrm{~min}$ walk at $5 \mathrm{~km} \cdot \mathrm{hr}^{-1}$ on a $2 \%$ gradient, as specified by Moran et al., (2007).

\subsection{Physiological Measures}

Participants were asked to attend the laboratory in a euhydrated state, which was confirmed via a urine sample with a urine colour $\left(\mathrm{U}_{\text {col }}\right)$ of $\leq 3$, osmolarity $\left(\mathrm{U}_{\text {osm }}\right)$ of $<700 \mathrm{mOsm} \cdot \mathrm{kgH}_{2} \mathrm{O}^{-1}$ (Pocket PalOsmo, Vitech Scientific, Ltd), and urine specific gravity $\left(\mathrm{U}_{\mathrm{spg}}\right)$ of $<1.020$ (hand refractometer, Atago Co., Tokyo, Japan) (Sawka et al. 2007).

Nude body mass was recorded prior to and post each trial (Adam GFK 150 Body Scales, Connecticut, USA, accurate to $0.01 \mathrm{~kg}$ ). Weight whilst clothed was also recorded after the resting period in both trials to allow for metabolic heat production calculation. A Henley single use rectal temperature probe (449H, Henleys Medical, Hertfordshire, UK) was positioned $10 \mathrm{~cm}$ past the anal sphincter, and displayed on logging monitors (YSI, 4600 series, YSI, Hampshire, UK) to measure rectal temperature $\left(\mathrm{T}_{\mathrm{re}}\right)$. Contact skin thermistors were attached to the mid-belly of the pectoralis major, biceps brachii, rectus femoris, and gastrocnemius, and recorded via a 1000 series Squirrel Data Logger (Grant Instruments, Cambridgeshire, UK) for the measurement of mean skin temperature $\left(\mathrm{T}_{\text {skin }}\right)$. A Polar FT1 heart rate monitor (Polar electro, Kempele, Finald) was also positioned to give heart rate (HR) readings. Temperature and HR measures were recorded at the end of the resting period, and every 5min throughout the exercise period.

\subsection{Perceptual Measures}

Perceptions of effort and thermal sensation were assessed via ratings of perceived exertion (RPE), on a scale of 6-20 (Borg 1982), and a thermal sensation (TS) scale, from 0 "unbearably cold" to 8 "unbearably hot" (Young et al. 1987). Measures were recorded at the end of the rest period and then every 10min during exercise. A heat illness symptoms index (HISI) was also recorded prior to and post heat exposure. The HISI included 13 symptoms of heat illness that individuals rated as between 0 "no symptoms whatsoever" and 10 "so bad I have to stop or can't start" (Coris et al. 2006). 


\section{ACCEPTED MANUSCRIPT}

\subsection{Gas Analysis}

Ventilatory gases were collected throughout the HOTT and during the first 40min and last 20min of the HTT. The face mask was removed between gas analysis periods. Gases were analysed using 30sec averaging from a Metalyzer Sport analyzer (Cortex, Leipzig, Germany). $\dot{\mathrm{V}}_{2}$ and RER each minute were used to calculate $\dot{\mathrm{H}}_{\text {prod }}$.

\subsection{Derivative Calculations}

Metabolic heat production $\left(\dot{\mathrm{H}}_{\text {prod }}\right)$ was calculated as the difference between metabolic energy expenditure $(\dot{\mathrm{M}})$ and the external work rate $(\mathrm{W})$, and was recorded every minute during gas collection. $\dot{\mathrm{H}}_{\text {prod }}$ is expressed relative to body mass in W.kg ${ }^{-1}$ (Cramer and Jay 2014). External work rate was calculated as described by Gordon et al. (1983), with mass used being the combination of body mass of the participant and PPE (Dreger et al. 2006).

$$
\begin{aligned}
& \dot{M}(\text { Watts })=\dot{V} O_{2} \frac{\left(\frac{R E R-0.7}{0.3} e_{c}\right)+\left(\frac{1-R E R}{0.3} e_{f}\right)}{60} \times 1000 \\
& \dot{H}_{\text {prod }}\left(W k^{-1}\right)=(\dot{M}-W) / \text { Body Mass }
\end{aligned}
$$

where $e_{c}$ is the caloric equivalent per litre of oxygen for the oxidation of carbohydrates $(21.13 \mathrm{~kJ})$ and $e_{f}$ is the caloric equivalent per litre of oxygen for the oxidation of fat $(19.62 \mathrm{~kJ})$.

Mean skin temperature $\left(\mathrm{T}_{\text {skin }}\right)$ was calculated using the measurements taken from the contact skin thermistors (Ramanathan 1964) :

$$
T_{\text {skin }}\left({ }^{\circ} \mathrm{C}\right)=0.3\left(T_{\text {chest }}+T_{\text {upper arm }}\right)+0.2\left(T_{\text {upper leg }}+T_{\text {lower leg }}\right)
$$

Physiological strain index was calculated as per the equation (Moran et al. 1998):

$$
P S I=5\left(T_{r e} t-T_{r e 0}\right) \cdot\left(39.5-T_{r e o}\right)^{-1}+5\left(H R t-H R_{0}\right) \cdot\left(180-H R_{0}\right)^{-1}
$$

where $\mathrm{T}_{\mathrm{re}} t$ and $\mathrm{HR} t$ were simultaneous measurements taken every $5 \mathrm{~min}$ during the exposure, and $\mathrm{T}_{\mathrm{re} 0}$ and $\mathrm{HR}_{0}$ represent baseline states.

Sweat rate (SR) was calculated at the end of heat exposure. 
SR $\left(\right.$ L. $\left.h^{-1}\right)=$ Body Mass pre - Body Mass post / Time (minutes $) * 60$

\subsection{Statistical Analysis}

Data were analysed using IBM SPSS 22. Data were checked for normality using the Shapiro-Wilk method. Numerous reliability and validity statistics were conducted. Intra-class correlation coefficient (ICC) with 95\% confidence intervals (95\% CI) were calculated using an absolute agreement, two-way mixed-effects model, as a measure of test-retest reliability between HOTT sessions and a measure of correlation between HOTT and HTT. An ICC of $>0.90$ was classified as a high correlation, $0.70-0.80$ as moderate, and below 0.70 as low (Vincent and Weir 1995). Typical error of the measurement (TEM) was also calculated (TEM $=\mathrm{SD}(\operatorname{diff}) / \sqrt{2})$ and is presented in both absolute values, and values relative to the respective means as a coefficient of variation (CV). A CV\% of $<10 \%$ will be considered acceptable (Stokes 1985). Bland-Altman plots with 95\% limits of agreements (LOA) were created with the individual participant differences between the trials plotted against the respective individual means. Acceptable mean bias levels and 95\% LOA for bland-altman plots for reliability assessment were selected a priori based on the reliability mean bias and LOA from the running heat tolerance test $\left(\right.$ Tre $-0.04^{\circ} \mathrm{C}\left(0.41^{\circ} \mathrm{C}, 0.33^{\circ} \mathrm{C}\right)$, Tskin $0.01^{\circ} \mathrm{C}\left(-0.38^{\circ} \mathrm{C}, 0.40^{\circ} \mathrm{C}\right)$, HR 1 b.min ${ }^{-1},(-8$ b.min ${ }^{1}, 6$ b.min $\left.{ }^{-1}\right)$ PSI $0.1(0.93,0.72)$, SR -0.13 L.hr ${ }^{-1},\left(0.49\right.$ L.hr $^{-1}, 023$ L.hr $\left.{ }^{-1}\right)$, RPE $0(-2,2)$, TS $(0(-1,1))$ (Mee et al. 2015a). Acceptable mean bias levels for bland-altman plots for validity comparisons were identified a priori based on the smallest detectable changes in heat tolerance noted from heat acclimation studies $\left(\mathrm{T}_{\mathrm{re}}<0.2^{\circ} \mathrm{C}, \mathrm{HR}<5 \mathrm{~b} . \mathrm{min}^{-1}, \mathrm{~T}_{\text {skin }}<0.5^{\circ} \mathrm{C}\right.$, PSI $<1, \mathrm{SR}<0.5 \mathrm{~L} . \mathrm{hr}^{-1}, \mathrm{TS}<0.5, \mathrm{RPE}$ <1) (Gibson et al. 2015; Mee et al. 2015b; Tyler et al. 2016). LOA criteria could not be identified a priori for validity comparisons as no previous validity comparisons to HTT have been performed. To identify differences between trials for all measures, paired sample T-tests were also conducted. Statistical significance was set at $\mathrm{p} \leq 0.05$.

To identify differences between tolerance groups, a two way mixed method ANOVA was performed. Greenhouse-Geisser corrections were used if Mauchly's test of sphericity was violated. Follow up Bonferroni corrected T-tests were conducted to identify if differences were present at $20 \mathrm{~min}$ and 


\section{ACCEPTED MANUSCRIPT}

40min, with the corrected alpha level of $\mathrm{p} \leq 0.025$ used. Data is reported as mean \pm standard deviation.

\section{RESULTS}

\subsection{Validity of Variables}

All participants were in a hydrated state at the beginning of the HTT $\left(\mathrm{U}_{\mathrm{col}} 2 \pm 1, \mathrm{U}_{\mathrm{osm}} 307 \pm 203\right.$

mOsm.kgH $\left.\mathrm{O}^{-1}, \mathrm{U}_{\text {spg }} 1.009 \pm 0.006\right)$ and HOTT $\left(\mathrm{U}_{\text {col }} 2 \pm 1, \mathrm{U}_{\text {osm }} 211 \pm 136 \mathrm{mOsm} . \mathrm{kgH}_{2} \mathrm{O}^{-1}, \mathrm{U}_{\text {spg }} 1.006\right.$ $\pm 0.004)$ with no differences in $\mathrm{U}_{\text {col }}(\mathrm{p}=0.79), \mathrm{U}_{\text {osm }}(\mathrm{p}=0.072)$, or $\mathrm{U}_{\mathrm{spg}}(\mathrm{p}=0.096)$ between trials. The mean speed needed to achieve $6 \mathrm{~W} . \mathrm{kg}^{-1}$ during the HOTT was $5.1 \pm 0.4 \mathrm{~km} . \mathrm{hr}^{-1}$, ranging from 4 $6 \mathrm{~km} . \mathrm{hr}^{-1}$ across participants. The mean $\dot{H}_{\text {prod }}$ achieved at the end of the HTT was $4.8 \pm 1.0 \mathrm{~W} . \mathrm{kg}^{-1}$, ranging from $2.9-6.3 \mathrm{~W} \cdot \mathrm{kg}^{-1}$.

\subsubsection{Physiological Measures}

Values of ICC, TEM and LOA for key physiological and perceptual measures are presented in Table 1. Moderate to weak correlations were present for peak $T_{\mathrm{re}}(\mathrm{ICC}=0.86)$, change in $\mathrm{T}_{\mathrm{re}}\left(\Delta \mathrm{T}_{\mathrm{re}}\right)(\mathrm{ICC}=$ 0.68), peak HR $(\mathrm{ICC}=0.58)$, change in HR $(\Delta \mathrm{HR})(\mathrm{ICC}=0.55)$ and peak PSI $(\mathrm{ICC}=0.64)$ between HTT and HOTT. $\mathrm{T}_{\text {re }}$ also demonstrated a low TEM and CV. No correlations were presented for peak $\mathrm{T}_{\text {skin }}(\mathrm{ICC}=0.09)$ and $\mathrm{SR}(\mathrm{ICC}=0.19)$. Figure 1 demonstrates acceptable mean bias with all data points within LOA of peak $\mathrm{T}_{\mathrm{re}}$ and peak PSI between trials. Figure 1 also presents a large mean bias for peak HR.

In addition, paired samples T-tests revealed no differences between HTT and HOTT for peak $\mathrm{T}_{\mathrm{re}}$ $(\mathrm{p}=0.182), \Delta \mathrm{T}_{\mathrm{re}}(\mathrm{p}=0.098)$, and $\Delta \mathrm{T}_{\text {skin }}(\mathrm{p}=0.288)$. Differences were present for peak $\mathrm{HR}\left(\mathrm{t}_{(16)}=5.705\right.$, $\mathrm{p}<0.001), \Delta \mathrm{HR}\left(\mathrm{t}_{(16)}=4.196, \mathrm{p}=0.001\right)$, peak PSI $\left(\mathrm{t}_{(16)}=2.510, \mathrm{p}=0.023\right)$, peak $\mathrm{T}_{\text {skin }}\left(\mathrm{t}_{(16)}=8.296\right.$, $\mathrm{p}<0.001)$, and $\mathrm{SR}\left(\mathrm{t}_{(16)}=3.539, \mathrm{p}=0.003\right)$.

\subsubsection{Perceptual Measures}

Weak to moderate correlations were present for RPE (ICC $=0.58$ ), and HISI (ICC $=0.87$ ), with no correlation present for TS $(\mathrm{ICC}=0.36)$. T-tests revealed no differences in HISI scores between trials, 


\section{ACCEPTED MANUSCRIPT}

$(\mathrm{p}=0.481)$. Differences were present for $\operatorname{RPE}\left(\mathrm{t}_{(16)}=2.182, \mathrm{p}=0.044\right)$ and TS $\left(\mathrm{t}_{(16)}=2.380, \mathrm{p}=0.030\right)$ between HTT and HOTT.

\subsection{Validity of Tolerance}

Based on the $T_{r e}$ heat intolerance criteria set by Moran et al. (2007) $\left(\mathrm{T}_{\mathrm{re}}>38.5^{\circ} \mathrm{C}\right), 11$ participants were classified as heat intolerant in both HTT and HOTT. All of the 11 also exhibited a $\Delta \mathrm{T}_{\mathrm{re}}$ of $>0.45^{\circ} \mathrm{C}$ in the final $60 \mathrm{~min}$ of the HTT, as suggested by Amit et al. (2013). One participant was classed as heat intolerant in HTT but not in HOTT. Only one participant met the $\mathrm{T}_{\mathrm{re}}$ criteria for heat tolerance $\left(\mathrm{T}_{\mathrm{re}} \leq 38.0^{\circ} \mathrm{C}\right)$, with a $\mathrm{T}_{\mathrm{re}}$ of $37.58^{\circ} \mathrm{C}$ in the HOTT and $37.79^{\circ} \mathrm{C}$ in the HTT. Of the remaining four participants who sat between $38.0^{\circ} \mathrm{C}$ and $38.5^{\circ} \mathrm{C}$, two had a $\mathrm{HR}$ above the heat intolerance criteria of $145 \mathrm{~b} \cdot \mathrm{min}^{-1}$. All participants displayed a peak HR above $145 \mathrm{~b} \cdot \mathrm{min}^{-1}$ in the HOTT.

When grouped by classification in the HOTT, heat intolerant participants had a greater peak $\mathrm{T}_{\mathrm{re}}$ of $38.78 \pm 0.19^{\circ} \mathrm{C}$ compared to $38.22 \pm 0.33^{\circ} \mathrm{C}$ for those below the criteria set point $(\mathrm{p}<0.001)$. A two way mixed method ANOVA revealed a significant difference in $\Delta \mathrm{T}_{\mathrm{re}}$ between the groups $(\mathrm{p}=0.038)$. The heat intolerant group exhibited changes at half way and the end of the walk test of $0.05 \pm 0.12^{\circ} \mathrm{C}$ and $1.45 \pm 0.22^{\circ} \mathrm{C}$ vs. $0.36 \pm 12^{\circ} \mathrm{C}$ and $1.02 \pm 0.27^{\circ} \mathrm{C}$ for those below the criteria point $(\mathrm{p}<0.001$, $\mathrm{p}=0.003$, respectively), as displayed in Figure 2 .

\subsection{Reliability}

Hydration requirements were met by all participants at the start of HOTT1 $\left(\mathrm{U}_{\text {col }} 2 \pm 1, \mathrm{U}_{\text {osm }} 211 \pm 136\right.$ mOsm.kgH $\left.\mathrm{O}^{-1}, \mathrm{U}_{\text {spg }} 1.006 \pm 0.004\right)$ and HOTT2 $\left(\mathrm{U}_{\text {col }} 2 \pm 1, \mathrm{U}_{\text {osm }} 299 \pm 220 \mathrm{mOsm} \cdot \mathrm{kgH}_{2} \mathrm{O}^{-1}, \mathrm{U}_{\text {spg }}\right.$ $1.011 \pm 0.012)$, with no differences between trials for $\mathrm{U}_{\text {col }}(\mathrm{p}=0.64), \mathrm{U}_{\mathrm{osm}}(\mathrm{p}=0.37), \mathrm{U}_{\mathrm{spg}}(\mathrm{p}=0.13)$. Table 2 presents values of ICC, TEM and LOA for key physiological and perceptual measures for the reliability between the two trials.

\subsubsection{Physiological Measures}




\section{ACCEPTED MANUSCRIPT}

Moderate to strong correlations were observed between HOTT1 and HOTT2 for peak $\mathrm{T}_{\mathrm{re}}(\mathrm{ICC}=0.98)$, $\Delta \mathrm{T}_{\text {re }}(\mathrm{ICC}=0.77)$, peak HR $(\mathrm{ICC}=0.99), \Delta \mathrm{HR}(\mathrm{ICC}=0.94)$, peak $\mathrm{T}_{\text {skin }}(\mathrm{ICC}=0.78)$, peak PSI (ICC=0.98), and SR (ICC=0.96). All physiological measures demonstrated acceptable TEM, CV, and mean bias between trials. See Figure 3 for mean bias and LOA, and line of equality for peak $T_{r e}$, peak HR, and peak PSI between HOTT trials.

T-tests indicated that there were no differences between HOTT1 and HOTT2 in peak $T_{\text {re }}, \Delta T_{\text {re, }}$, peak $\mathrm{HR}, \Delta \mathrm{HR}$, peak $\mathrm{T}_{\text {skin }}, \Delta \mathrm{T}_{\text {skin, }}$ peak PSI, and SR (p>0.05).

\subsubsection{Perceptual Measures}

Strong correlations were observed between HOTT1 and HOTT2 in peak RPE (ICC $=0.96$ ), TS (ICC $=0.87$ ), and HISI $(\mathrm{ICC}=0.95)$. Acceptable $\mathrm{CV}$ and mean bias are present between trials in RPE and TS. There were no differences in peak RPE $(\mathrm{p}=0.432)$, TS $(\mathrm{p}=1.00)$, and HISI $(\mathrm{p}=0.515)$.

\subsubsection{Heat Tolerance}

All heart rates exceeded the heat tolerance criteria set by Moran et al. (2007). When classified by peak $\mathrm{T}_{\mathrm{re}}$ five participants were heat intolerant, and all individuals were classified the same in both HOTT1 and HOTT2. One participant withdrew due to nausea at 30min in both HOTT and was therefore also classified in the heat intolerant group, making six in total. No individual met the heat tolerant criteria of $38.0^{\circ} \mathrm{C}$.

\section{DISCUSSION}

The aim of the study was to assess the validity and reliability of the HOTT, a heat tolerance test purposefully designed to replicate uncompensable heat strain when wearing protective clothing, and allow for inter-individual comparisons using a set $\dot{\mathrm{H}}_{\text {prod. }}$. The HOTT was able to replicate HTT core temperature responses, and results were replicated following a 5 day period. Consequently, hypothesis (1) and (2) can both be accepted.

\subsection{Validity of Variables}




\section{ACCEPTED MANUSCRIPT}

Peak $\mathrm{T}_{\mathrm{re}}$ displayed the greatest level of agreement between HTT and HOTT, with a TEM of $0.19^{\circ} \mathrm{C}$ $(0.49 \%)$, a strong ICC $(0.86)$, and a small mean bias $0.09^{\circ} \mathrm{C}\left(-0.43^{\circ} \mathrm{C}, 0.62^{\circ} \mathrm{C}\right)$. It is elevated $\mathrm{T}_{\mathrm{re}}$, combined with neuropsychiatric impairment, that is used to diagnose heat illnesses, with a $T_{\mathrm{re}}$ of $40.5^{\circ} \mathrm{C}$ indicating heat stroke (Casa et al. 2015), and therefore is one of the most important predictors of heat tolerance. Being able to predict if an individual is likely to suffer an exertional heat illness is a key reason why heat tolerance tests may be used. In an occupational setting, this could indicate which individuals need to have shorter exposure times, closer monitoring, or acclimation periods, to reduce the risk of heat illness.

HR showed a moderate level of agreement between HTT and HOTT, however HOTT had a bias of 22 b. $\min ^{-1}$ greater than HTT. The additional cardiovascular strain was caused by the environmental conditions, as HR increased to raise skin blood flow and facilitate evaporative heat loss (Stewart et al. 2014). However, the protective clothing reduces the ability for individuals to dissipate heat as sweat evaporation is prevented (Petruzzello et al. 2009). Therefore HR continued to rise in an attempt to regain thermal balance, but the uncompensable environment prevented this from occurring.

The strong agreement between HOTT and HTT for HISI, suggests that the HOTT induces a similar subjective symptoms response to HTT, alongside the similar $\mathrm{T}_{\mathrm{re}}$ response. Wearing protective clothing and maintaining a $\dot{\mathrm{H}}_{\text {prod }}$ of $6 \mathrm{~W} \cdot \mathrm{kg}^{-1}$, instead of a continuous $5 \mathrm{~km} \cdot \mathrm{h}^{-1}$ walk, enabled a greater rate of rise in both physiological and perceptual measures in the HOTT, despite the test being 80min shorter in duration. The rate of rise for $\mathrm{T}_{\mathrm{re}}$ was $0.03 \pm 0.01^{\circ} \mathrm{C} \cdot \mathrm{min}^{-1}$ in the HOTT vs. $0.01 \pm 0.00^{\circ} \mathrm{C}$ in the HTT. Setting the test by $\dot{\mathrm{H}}_{\text {prod }}$ rather than by speed allows comparisons to be made between individuals of a heterogenous group, and also negates the effect of training status and fat mass change during intra-individual comparisons (Cramer and Jay 2014).

\subsection{Validity of Tolerance}

Based on Moran's $\mathrm{T}_{\mathrm{re}}$ criteria 16 of 17 participants were classified the same in both the HOTT and HTT. The HOTT was also successful at classifying individuals as heat intolerant or not, with statistical differences in peak $\mathrm{T}_{\mathrm{re}}$ and $\Delta \mathrm{T}_{\mathrm{re}}$ present between the groups. Peak $\mathrm{T}_{\mathrm{re}}$ was $0.56^{\circ} \mathrm{C}$ greater in 


\section{ACCEPTED MANUSCRIPT}

the intolerant group, which is smaller than the $0.81^{\circ} \mathrm{C}$ difference in groups noted by Moran et al. (2004). A smaller difference between groups is likely due to individual participant differences, as this study found little bias $\left(0.09^{\circ} \mathrm{C}\right)$ between the two tolerance tests. A greater proportion of participants were classified as heat intolerant than previously noted (Moran et al. 2004), it is postulated that this may be due to the use of military individuals in previous studies, who are likely to have a superior level of aerobic fitness to the students who participated in this study. In addition, the participants in this study were not heat acclimated, with testing conducted during Autumn and Winter months, and consequently may be more likely to have an increased sensitivity to heat than participants of previous research conducted in hotter climates (Epstein 1990; Amit et al. 2012).

Although Moran et al (2007) take a dichotomous approach to heat tolerance, in that individuals are either heat tolerant or heat intolerant, six participants displayed $\mathrm{T}_{\mathrm{re}}$ responses that fit neither group. This indicates that heat tolerance should instead be viewed as a continuum, as previously suggested by Mee et al. (2015). Those individuals classified in neither group would therefore sit in the middle of the continuum. Individuals can move along the continuum by becoming more or less tolerant to the heat. This may be of particular use in an occupational setting as a way of identifying individuals who are at risk and monitoring their progress. Consequently, a continuum based approach is advised when interpreting individuals' responses.

\subsection{Reliability}

The HOTT demonstrates good reliability, with those who were heat intolerant distinguished as such in both HOTT1 and HOTT2. Furthermore, key measures of heat acclimation, such as peak $\mathrm{T}_{\mathrm{re}}$, peak HR, peak $\mathrm{T}_{\text {skin }}$ and SR (Moran et al. 2007; Sawka et al. 2011), all demonstrate strong correlations between the trials, with TEM and CV suggesting low intra-individual variability.

There has been no previous assessment of the reliability of the HTT, and so comparison between the tests on this matter cannot be made. However the TEM and $\mathrm{CV}$ of peak $\mathrm{T}_{\mathrm{re}},\left(0.08^{\circ} \mathrm{C}, 0.2 \%\right)$, peak $\mathrm{HR}$ (2 b. $\left.\mathrm{min}^{-1}, 1 \%\right)$, and SR (0.12 L.hr $\left.{ }^{-1}, 9.9 \%\right)$ are similar to that reported by Mee et al., (2015) when assessing the reliability of a $9 \mathrm{~km} \cdot \mathrm{h}^{-1} 30 \mathrm{~min}$ running heat tolerance test (peak $\mathrm{T}_{\mathrm{re}}: 0.13^{\circ} \mathrm{C}, 0.34 \%$, peak 


\section{ACCEPTED MANUSCRIPT}

HR: 2 b. $\mathrm{min}^{-1}, 1 \%$, SR: $\left.0.16 \mathrm{~L}^{-1} \mathrm{hr}^{-1}, 9 \%\right)$. The findings are also in line with the $\mathrm{T}_{\mathrm{re}} \mathrm{TEM}(\mathrm{CV} \%)$ of $0.20^{\circ} \mathrm{C}(0.3 \%)$ (Hayden et al. 2004), $0.14{ }^{\circ} \mathrm{C}(0.4 \%)$ (Willmott et al. 2015), and aural temperature of $0.10^{\circ} \mathrm{C}(0.6 \%)$ (Brokenshire et al. 2009) previously reported from different cycling heat exposure tests of 30-60min in duration. The HOTT is therefore a test that offers the same levels of reliability as other tolerance tests, and consequently is a good alternative for use in an occupational setting where protective clothing is worn, as it better replicates the conditions experienced by the participants.

\subsection{Application}

The HOTT can be used to assess heat tolerance, with interpretation of responses along a continuum recommended. From an application perspective, a colour coded continuum could be proposed as it may be easily interpretable, with those exhibiting responses of $<38.0^{\circ} \mathrm{C}$ sitting in a "green zone", individuals who are $38.0^{\circ} \mathrm{C}$ to $38.5^{\circ} \mathrm{C}$ in a "yellow zone", and $>38.5^{\circ} \mathrm{C}$ in a "red zone". Those individuals who are just beyond the "green zone" into the "yellow zone" would then be viewed as better able to cope in the heat than an individual at the far end of the "red zone". Individuals who present further into the "red zone" can then be selected for acute and chronic interventions to improve their ability to cope in the heat. In addition, these individuals could then be monitored to see if they shift to the left to the early "red zone" or "yellow zone" with interventions, which using dichotomous heat tolerance and intolerance criteria would not reflect. For the fire service it is often reaching a core temperature of $39.0^{\circ} \mathrm{C}$ which is a cut off point for exposure, and therefore knowing a firefighter is able to tolerate an uncompensable environment, for the duration a breathing apparatus lasts, without reaching this temperature is of key importance.

The HOTT also uses a set $\dot{\mathrm{H}}_{\text {prod }}$ which controls for changes in fitness level that may occur, therefore offering a more valid measurement of heat tolerance alterations. From a research perspective this will also allow inter-individual comparisons to be made, and consequently gives the HOTT a clear advantage over the HTT, which uses a fixed walking speed, for identifying and monitoring changes in the heat tolerance of individuals. The ability to compare individuals within a team or crew may enable resources, time or funding to be specifically targeted to those further towards the "red zone" and most at risk of a heat illness. In addition, the HOTT lasts for 40min instead of 120min, making it more 


\section{ACCEPTED MANUSCRIPT}

convenient to administer. The HOTT could be employed to identify new firefighter recruits' heat tolerance, as new recruits are at particular risk of heat illnesses during their first fire training sessions, having had no prior experience of the conditions. Currently, instructors are unable to predict which individuals within a cohort may be at greater risk. The HOTT may also be used within the fire service to monitor those identified as having a low tolerance to heat, in the aim to move them along the continuum. In any occupation involving physical activity in protective clothing, the HOTT could be used to safely monitor an individual's return to work following an occurrence of exertional heat exhaustion.

\subsection{Limitations}

No females were used as part of this study. It has previously been suggested that the criteria set points for tolerance using the HTT need to be re-evaluated when testing females, due to the possible thermoregulatory differences between sexes (Amit et al. 2012). Criteria for females undertaking the HOTT should be considered in future studies. Furthermore, it was not within the scope of this research to investigate the impact that heat acclimation status or others factors that may impact heat tolerance has on the response of individuals to the HOTT. Future research should investigate how interventions may progresses tolerance responses along the continuum. In addition, individuals did not exercise at $6 \mathrm{~W} \cdot \mathrm{kg}^{-1}$ from the beginning of the test, with the first $15 \mathrm{~min}$ varying for each individual as speed was adjusted to achieve the desired $\dot{\mathrm{H}}_{\text {prod. }}$. However, this enables individuals to only have to complete one visit to the laboratory for a HOTT to be conducted, therefore increasing the practicality of the protocol. Whilst the HOTT offers a more ecologically valid comparison to uncompensable heat stress environments, it does require specialist equipment, which could hinder its use where research equipment is not accessible. Consequently, further research should be conducted to develop a simplified field version of the test that can be applied when resources are minimal.

\section{CONCLUSION}

This study demonstrates that the HOTT is a reliable alternative to the HTT. The test offers a closer representation of the type of heat strain experienced by those who wear personal protective clothing. 


\section{ACCEPTED MANUSCRIPT}

It is also practically suitable, in that only one visit is required and the test is of a much shorter duration than the HTT. In addition, the use of a set $\dot{\mathrm{H}}_{\text {prod }}$ to determine the speed of the test enables both intra and inter individual comparisons to be conducted. Therefore, it is suggested that the HOTT is used when assessing the heat tolerance of individuals who wear protective clothing and work in an uncompensable heat stress environment.

\section{FUNDING}

This research did not receive any specific grant from funding agencies in the public, commercial, or not-for-profit sectors.

Declarations of interest: None

\section{REFERENCES}

Amit D, Ketko I, Yanovich R, et al (2013) Refining the distinction between heat tolerant and intolerant individuals during a Heat tolerance test. J Therm Biol 38:539-542. doi: 10.1016/j.jtherbio.2013.09.005

Amit D, Makranz C, Moran D, et al (2012) Heat tolerance in women-Reconsidering the criteria. Aviat Sp Environ Med 83:58-60. doi: 10.3357/ASEM.3130.2012

Binkley HM, Beckett J, Casa DJ, et al (2002) National Athletic Trainers' Association Position Statement : Exertional Heat Illnesses. J Athl Train 37:329-343. doi: 10.4085/1062-6050-50-907

Borg GA (1982) Psychophysical bases of perceived exertion. Med Sci Sports Exerc 14:377-81.

Brokenshire CS, Armstrong N, Williams CA (2009) The reliability of adolescent thermoregulatory responses during a heat acclimation protocol. J Sport Sci Med 8:689-695. 


\section{ACCEPTED MANUSCRIPT}

Brotherhood JR (2008) Heat stress and strain in exercise and sport. J Sci Med Sport 11:6-19. doi: 10.1016/j.jsams.2007.08.017

Casa DJ, DeMartini JK, Bergeron MF, et al (2015) National Athletic Trainers' Association Position Statement: Exertional Heat Illnesses. J Athl Train 50:986-1000. doi: 10.4085/1062-605050.9.07

Cheung SS, McLellan TM, Tenaglia S (2000) The thermophysiology of uncompensable heat stress. Physiological manipulations and individual characteristics. Sport Med 29:329-59.

Coris EE, Walz SM, Duncanson R, et al (2006) Heat illness symptom index (HISI): a novel instrument for the assessment of heat illness in athletes. South Med J 99:340-345.

Cramer MN, Jay O (2014) Selecting the correct exercise intensity for unbiased comparisons of thermoregulatory responses between groups of different mass and surface area. J Appl Physiol 116:1123-32. doi: 10.1152/japplphysiol.01312.2013

Cramer MN, Jay O, Ainslie P, et al (2015) Explained variance in the thermoregulatory responses to exercise: the independent roles of biophysical and fitness/fatness-related factors. J Appl Physiol 119:982-9. doi: 10.1152/japplphysiol.00281.2015

Dervis SM, Coombs GB, Chaseling GK, et al (2015) A comparison of thermoregulatory responses to exercise between mass-matched groups with large differences in body fat. J Appl Physiol jap.00906.2015. doi: 10.1152/japplphysiol.00906.2015

Dreger RW, Jones RL, Petersen SR (2006) Effects of the self-contained breathing apparatus and fire protective clothing on maximal oxygen uptake. Ergonomics 49:911-20. doi: $10.1080 / 00140130600667451$

Drust B, Waterhouse J, Atkinson G, et al (2005) Circadian rhythms in sports performance--an update. Chronobiol Int 22:21-44. doi: 10.1081/CBI-200041039

Eglin CM (2007) Physiological Responses to Fire-fighting : thermal and Metabolic Considerations. J Human-Environment Syst 10:7-18. 


\section{ACCEPTED MANUSCRIPT}

Epstein Y (1990) Heat intolerance: predisposing factor or residual injury? Med Sci Sports Exerc 22:29-35.

Gibson OR, Mee JA., Tuttle JA., et al (2015) Isothermic and fixed intensity heat acclimation methods induce similar heat adaptation following short and long-term timescales. J Therm Biol 4950:55-65. doi: 10.1016/j.jtherbio.2015.02.005

Gordon MJ, Goslin BR, Graham T, Hoare J (1983) Comparison between load carriage and grade walking on a treadmill. Ergonomics 26:289-298. doi: 10.1080/00140138308963342

Hargreaves M (2008) Physiological limits to exercise performance in the heat. J Sci Med Sport 11:66-71. doi: 10.1016/j.jsams.2007.07.002

Hayden G, Milne HC, Patterson MJ, Nimmo MA (2004) The reproducibility of closed-pouch sweat collection and thermoregulatory responses to execise-heat stress. Eur J Appl Physiol 91:748751. doi: 10.1007/s00421-004-1057-x

Jay O, Bain AR, Deren TM, et al (2011) Large differences in peak oxygen uptake do not independently alter changes in core temperature and sweating during exercise. Am J Physiol 301:R832-41. doi: 10.1152/ajpregu.00257.2011

Kenny GP, Yardley J, Brown C, et al (2010) Heat stress in older individuals and patients with common chronic diseases. Cmaj 182:1053-1060. doi: 10.1503/cmaj.081050

Lisman P, Kazman JB, Connor COLFGO, et al (2014) Heat Tolerance Testing : Association Between Heat Intolerance and Anthropometric and Fitness Measurements. doi: 10.7205/MILMED-D-14-00169

Mee JA., Doust J, Maxwell NS (2015a) Repeatability of a running heat tolerance test. J Therm Biol 49-50:91-97. doi: 10.1016/j.jtherbio.2015.02.010

Mee JA., Gibson OR, Doust J, Maxwell NS (2015b) A comparison of males and females' temporal patterning to short- and long-term heat acclimation. Scand J Med Sci Sport 25:250-258. doi: $10.1111 / \mathrm{sms} .12417$ 


\section{ACCEPTED MANUSCRIPT}

Moran DS, Erlich T, Epstein Y (2007) The heat tolerance test: an efficient screening tool for evaluating susceptibility to heat. J Sport Rehabil 16:215-221.

Moran DS, Heled Y, Still L, et al (2004) Assessment of heat tolerance for post exertional heat stroke individuals. Med Sci Monit 10:CR252-R257.

Moran DS, Shitzer A, Pandolf KB (1998) A physiological strain index to evaluate heat stress. Am J Physiol 275:R129-34.

Périard JD, Racinais S, Sawka MN (2015) Adaptations and mechanisms of human heat acclimation: Applications for competitive athletes and sports. Scand J Med Sci Sport 25:20-38. doi: $10.1111 / \mathrm{sms} .12408$

Petruzzello SJ, Gapin JI, Snook E, Smith DL (2009) Perceptual and physiological heat strain: examination in firefighters in laboratory- and field-based studies. Ergonomics 52:747-754. doi: $10.1080 / 00140130802550216$

Ramanathan NL (1964) A new weighting system for mean surface temperature of the human body. J Appl Physiol 19:531-533.

Sawka MN, Burke LM, Eichner ER, et al (2007) American College of Sports Medicine position stand. Exercise and fluid replacement. Med Sci Sports Exerc 39:377-90. doi:

$10.1249 / \mathrm{mss} .0 \mathrm{~b} 013 \mathrm{e} 31802 \mathrm{ca} 597$

Sawka MN, Leon LR, Montain SJ, Sonna LA (2011) Integrated physiological mechanisms of exercise performance, adaptation, and maladaptation to heat stress. Compr Physiol 1:1883-1928. doi: $10.1002 /$ cphy.c100082

Selkirk GA, Mclellan TM, Stapleton JM, et al (2001) Influence of aerobic fitness and body fatness on tolerance to uncompensable heat stress. J Appl Physiol 91:2055-2063.

Stewart IB, Stewart KL, Worringham CJ, Costello JT (2014) Physiological tolerance times while wearing explosive ordnance disposal protective clothing in simulated environmental extremes. PLoS One 9:e83740. doi: 10.1371/journal.pone.0083740 


\section{ACCEPTED MANUSCRIPT}

Stokes M (1985) Reliability and repeatability of methods for measuring muscle in physiotherapy.

Physiother Theory Pract 1:71-76. doi: 10.3109/09593988509163853

Taylor NAS, Cotter JD (2006) Heat adaptation: Guidelines for the optimisation of human performance. Int Sport J 7:33-57. doi: 10.1037/a0029149

Tyler CJ, Reeve T, Hodges GJ, Cheung SS (2016) The Effects of Heat Adaptation on Physiology, Perception and Exercise Performance in the Heat: A Meta-Analysis. Sport Med 46:1771. doi: $10.1007 / \mathrm{s} 40279-016-0572-3$

Vincent WJ, Weir JP (1995) Statistics in kinesiology.

Willmott a. GB, Hayes M, Dekerle J, Maxwell NS (2015) The reliability of a heat acclimation state test prescribed from metabolic heat production intensities. J Therm Biol 53:38-45. doi: 10.1016/j.jtherbio.2015.08.008

Young AJ, Sawka MN, Epstein Y, et al (1987) Cooling different body surfaces during upper and lower body exercise. J Appl Physiol 63:1218-23. 


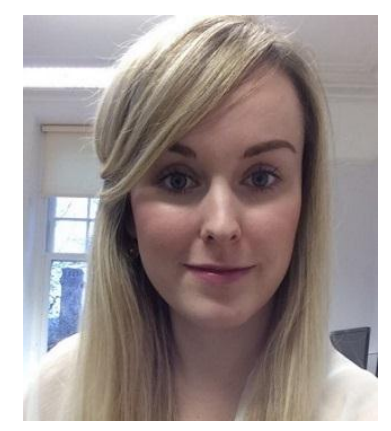

Miss Emily Watkins completed her B.Sc. (Hons) degree in Sport and Exercise Science in 2014 at the University of Brighton. She began her Ph.D. at the University in October 2014, working with Fire Service Instructors to investigate their heat tolerance and immunological responses to frequent heat exposures. Emily is also a Technical Instructor for the Sport and Exercise Science degree.

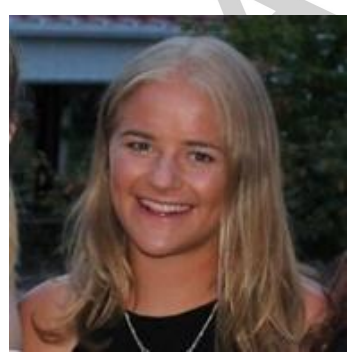




\section{ACCEPTED MANUSCRIPT}

Miss Jemma Gibbons graduated from the University of Brighton in 2017 with a B.Sc. (Hons) in Sport and Exercise Science. Jemma has now gone on to continue her studies with a PGCE in Secondary Biology at Nottingham Trent University.

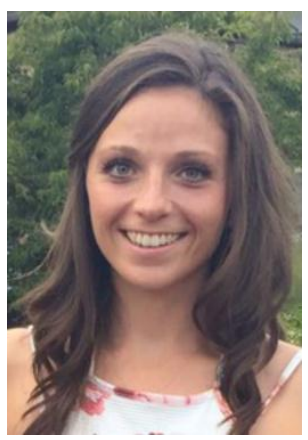

Miss Yanoula Dellas completed her B.Sc. (Hons) under-graduate degree in Sport and Exercise Science in 2016 at the University of Brighton. She focused her dissertation research on validating heat tolerance tests for the Fire Service. Her main research interest is in environmental physiology.

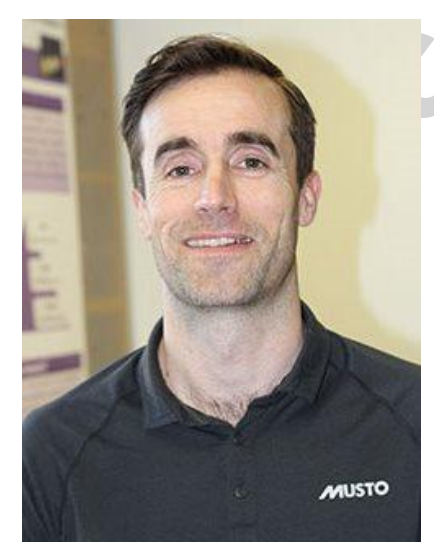

Dr Mark Hayes Mark studied a B.Sc. (Hons.) Sport and Exercise Science Degree at the University of Brighton, before moving to a full-time lecturing position at Sus- sex Downs 


\section{ACCEPTED MANUSCRIPT}

College, Eastbourne. Mark then returned to the University of Brighton as a lecturer in sport and exercise science in 2011, where he completed his Ph.D., entitled "The effect of progressive heat acclimation on games players performing intermittent-sprint exercise in the heat", in 2014. He teaches in the areas of sport and exercise physiology, environmental and expedition physiology, and was awarded one of the University of Brighton's Excellence in Facilitating and Empowering Learning Awards in 2013.

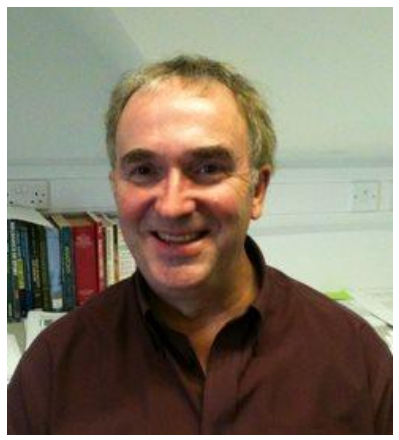

Dr. Peter Watt has published over 100 peer reviewed articles, 100 abstracts and acts as a reviewer and editor for several international journals. Dr. Watt's research focuses on measuring metabolic and physiological changes occurring in humans during exercise, with application to health related problems, e.g. diabetes, obesity. Dr. Watt has supervised 16 Ph.D. and 1 M.Phil. project and is an Associate Professor.

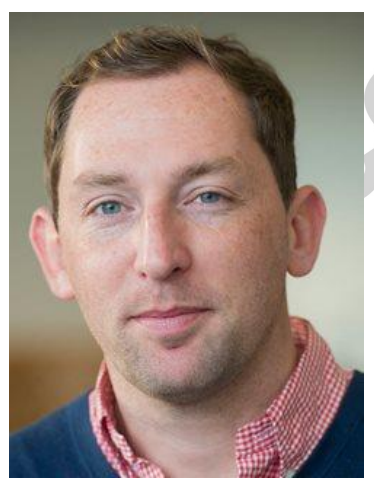

Dr. Alan Richardson's research focuses on the physiological changes and human tolerance to hypoxia and severe heat exposure. Dr. Richardson worked as a research exercise physiologist on the Centre for Aviation, Space and Extreme Environment Medicine Xtreme Everest 


\section{ACCEPTED MANUSCRIPT}

Project in 2007 and 2009. Since then Dr. Richardson has led research projects with the National Fire Service investigating the health and thermal loading of fire fighters and instructors. 


\section{ACCEPTED MANUSCRIPT}

Table 1 Validity of variables statistics between HOTT and HTT. Rectal temperature $\left(\mathrm{T}_{\mathrm{re}}\right)$, heart rate (HR), mean skin temperature $\left(\mathrm{T}_{\text {skin }}\right)$, physiological strain index (PSI), sweat rate (SR), rating of perceived exertion (RPE), thermal sensation (TS), and heat illness symptoms index (HISI). Scale ranges are presented in column headings for PSI, RPE, TS, and HISI.

\begin{tabular}{|c|c|c|c|c|c|c|c|c|}
\hline & $\begin{array}{l}\text { Peak } T_{\text {re }} \\
\left({ }^{\circ} \mathbf{C}\right)\end{array}$ & $\begin{array}{l}\text { Peak HR } \\
\left.\text { (b.min }{ }^{-1}\right)\end{array}$ & $\begin{array}{l}\text { Peak } \mathbf{T}_{\text {skin }} \\
\left({ }^{\circ} \mathbf{C}\right)\end{array}$ & $\begin{array}{l}\text { Peak PSI } \\
(0-10)\end{array}$ & $\begin{array}{l}\text { SR } \\
\left(\mathbf{L} . h r^{-1}\right)\end{array}$ & $\begin{array}{l}\text { Peak RPE } \\
(6-20)\end{array}$ & $\begin{array}{l}\text { Peak TS } \\
(0-8)\end{array}$ & $\begin{array}{l}\text { Peak } \\
\text { HISI } \\
(0- \\
130)\end{array}$ \\
\hline HTT & $38.67 \pm 0.42$ & $157 \pm 20$ & $\begin{array}{l}36.50 \pm \\
0.79\end{array}$ & $\begin{array}{l}7.17 \pm \\
1.50\end{array}$ & $0.94 \pm 0.17$ & $14 \pm 3$ & $6 \pm 1$ & $\begin{array}{l}23 \pm \\
17\end{array}$ \\
\hline HOTT & $38.58 \pm 0.36$ & $179 \pm 18$ & $\begin{array}{l}38.35 \pm \\
0.66\end{array}$ & $\begin{array}{l}7.97 \pm \\
1.20\end{array}$ & $1.30 \pm 0.42$ & $16 \pm 2$ & $7 \pm 0.5$ & $\begin{array}{l}25 \pm \\
13\end{array}$ \\
\hline $\begin{array}{l}\text { TEM } \\
\text { (CV\%) }\end{array}$ & $0.19(0.49)$ & $11(6.56)$ & 0.65 (1.74) & $\begin{array}{l}0.92 \\
(12.20)\end{array}$ & $\begin{array}{l}0.29 \\
(26.22)\end{array}$ & $2(14.23)$ & $0.5(8.88)$ & $\begin{array}{l}7 \\
(30.47\end{array}$ \\
\hline $\begin{array}{l}\text { Mean } \\
\text { bias } \\
\text { (LOA) }\end{array}$ & $\begin{array}{l}0.09 \\
(-0.43,0.62)\end{array}$ & $\begin{array}{l}-22 \\
(-52,9)\end{array}$ & $\begin{array}{l}-1.85 \\
(-3.66,- \\
0.05)\end{array}$ & $\begin{array}{l}-0.74 \\
(-3.35 \\
1.76)\end{array}$ & $\begin{array}{l}-0.36 \\
(-1.17 \\
0.46)\end{array}$ & $\begin{array}{l}-2 \\
(-8,4)\end{array}$ & $\begin{array}{l}-0.5 \\
(-2,1)\end{array}$ & $\begin{array}{l}-2 \\
(-22, \\
19)\end{array}$ \\
\hline $\begin{array}{l}\text { ICC } \\
(95 \% \text { CI })\end{array}$ & $\begin{array}{l}0.86 \\
(0.63,0.95) \\
p<0.001\end{array}$ & $\begin{array}{l}0.58 \\
(- \\
0.25,0.87) \\
p=0.001\end{array}$ & $\begin{array}{l}0.09 \\
(- \\
0.13,0.41) \\
p=0.217\end{array}$ & $\begin{array}{l}0.64 \\
(0.06,0.87) \\
p=0.011\end{array}$ & $\begin{array}{l}0.19 \\
(- \\
0.42,0.63) \\
p=0.258\end{array}$ & $\begin{array}{l}0.58 \\
(- \\
0.04,0.84) \\
\mathrm{p}=0.027\end{array}$ & $\begin{array}{l}0.36 \\
(- \\
0.42,0.74) \\
p=0.147\end{array}$ & $\begin{array}{l}0.87 \\
(0.64, \\
0.95) \\
\mathrm{p}<0.0 \\
01\end{array}$ \\
\hline
\end{tabular}


Table 2 Reliability statistics between HOTT1 and HOTT2. Rectal temperature $\left(\mathrm{T}_{\mathrm{re}}\right)$, heart rate $(\mathrm{HR})$, mean skin temperature $\left(\mathrm{T}_{\text {skin }}\right)$, physiological strain index (PSI), sweat rate (SR), rating of perceived exertion (RPE), thermal sensation (TS), and heat illness symptoms index (HISI). Scale ranges are presented in column headings for PSI, RPE, TS, and HISI.

\begin{tabular}{|c|c|c|c|c|c|c|c|c|}
\hline & $\begin{array}{l}\text { Peak T } \mathbf{T}_{\text {re }} \\
\left({ }^{\circ} \mathrm{C}\right)\end{array}$ & $\begin{array}{l}\text { Peak HR } \\
\text { (b.min }\end{array}$ & $\begin{array}{l}\text { Peak } \mathbf{T}_{\text {skin }} \\
\left({ }^{\circ} \mathbf{C}\right)\end{array}$ & $\begin{array}{l}\text { Peak PSI } \\
(0-10)\end{array}$ & $\begin{array}{l}\text { SR } \\
\left(\text { L.hr }^{-1}\right)\end{array}$ & $\begin{array}{l}\text { Peak RPE } \\
(6-20)\end{array}$ & $\begin{array}{l}\text { Peak TS } \\
(0-8)\end{array}$ & $\begin{array}{l}\text { Peak } \\
\text { HISI } \\
(0-130) \\
\end{array}$ \\
\hline HOTT1 & $\begin{array}{l}38.54 \pm \\
0.37\end{array}$ & $182 \pm 20$ & $\begin{array}{l}38.54 \pm \\
0.54\end{array}$ & $8.08 \pm 1.24$ & $1.21 \pm 0.46$ & $16 \pm 3$ & $7.5 \pm 0.5$ & $24 \pm 15$ \\
\hline HOTT2 & $\begin{array}{l}38.55 \pm \\
0.34\end{array}$ & $182 \pm 21$ & $\begin{array}{l}38.51 \pm \\
0.38\end{array}$ & $8.22 \pm 1.23$ & $1.27 \pm 0.39$ & $16 \pm 3$ & $7.5 \pm 0.5$ & $26 \pm 16$ \\
\hline $\begin{array}{l}\text { TEM } \\
\text { (CV\%) }\end{array}$ & $0.08(0.20)$ & $2(1.26)$ & $0.29(0.75)$ & $0.22(2.70)$ & $0.12(9.90)$ & $1(5.01)$ & $0.5(4.32)$ & $\begin{array}{l}5.05 \\
(20.44)\end{array}$ \\
\hline $\begin{array}{l}\text { Mean } \\
\text { bias } \\
\text { (LOA) }\end{array}$ & 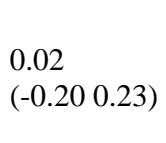 & $\begin{array}{l}0 \\
(-6,7)\end{array}$ & $\begin{array}{l}-0.03 \\
(-0.82- \\
0.77)\end{array}$ & $\begin{array}{l}-0.14 \\
(-0.47, \\
0.75)\end{array}$ & $\begin{array}{l}0.05 \\
(-0.29, \\
0.39)\end{array}$ & $\begin{array}{l}0 \\
(-2,2)\end{array}$ & $\begin{array}{l}0 \\
(-1,1)\end{array}$ & $\begin{array}{l}1.45 \\
(-12.55 \\
15.46)\end{array}$ \\
\hline $\begin{array}{l}\mathrm{ICC} \\
(95 \% \\
\mathrm{CI})\end{array}$ & $\begin{array}{l}0.98 \\
(0.92,0.99) \\
\mathrm{p}<0.001\end{array}$ & $\begin{array}{l}0.99 \\
(0.98,1.00) \\
\mathrm{p}<0.001\end{array}$ & $\begin{array}{l}0.78 \\
(0.14,0.94) \\
p=0.016\end{array}$ & $\begin{array}{l}0.98 \\
(0.93,0.99) \\
p<0.001\end{array}$ & $\begin{array}{l}0.96 \\
(0.85,0.99) \\
\mathrm{p}<0.001\end{array}$ & $\begin{array}{l}0.96 \\
(0.86,0.99) \\
p<0.001\end{array}$ & $\begin{array}{l}0.87 \\
(0.51,0.97), \\
p=0.002\end{array}$ & $\begin{array}{l}0.95 \\
(0.80,0.9 \\
9) \\
p<0.001\end{array}$ \\
\hline
\end{tabular}

Fig 1 Bland-Altman plots with 95\% limits of agreement and line of equality plots for peak physiological strain index (PSI) (A, B, respectively), peak rectal temperature $\left(\mathrm{T}_{\mathrm{re}}\right)(\mathrm{C}, \mathrm{D})$, and peak heart rate (HR) (E, F) between HOTT and HTT

Fig 2 Mean \pm SD Change in rectal temperature $\left(\Delta T_{\text {re }}\right)$ for intolerant $(n=11)$ vs tolerant $(n=6)$ individuals in HOTT, classified by Moran's $38.5^{\circ} \mathrm{C}$ criteria for intolerance. ${ }^{*}$ denotes significant differences between the groups, $\mathrm{p}<0.025$

Fig 3 Bland-Altman plots with 95\% limits of agreement and line of equality plots for peak physiological strain index (PSI) $\left(\mathrm{H}, \mathrm{I}\right.$, respectively), peak rectal temperature $\left(\mathrm{T}_{\mathrm{re}}\right)(\mathrm{J}, \mathrm{K})$, and peak heart rate (HR) (L, M) between HOTT1 and HOTT2 

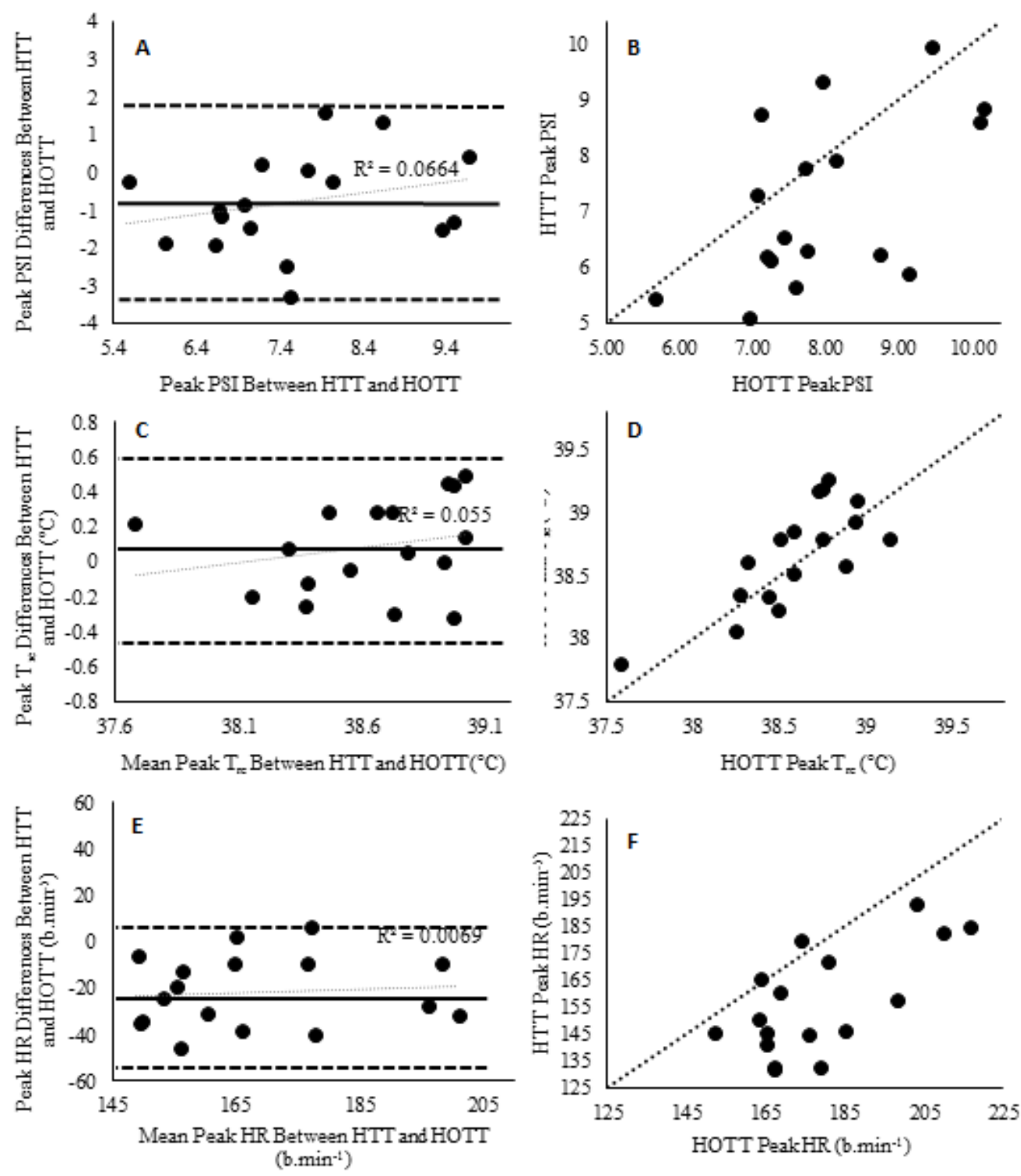


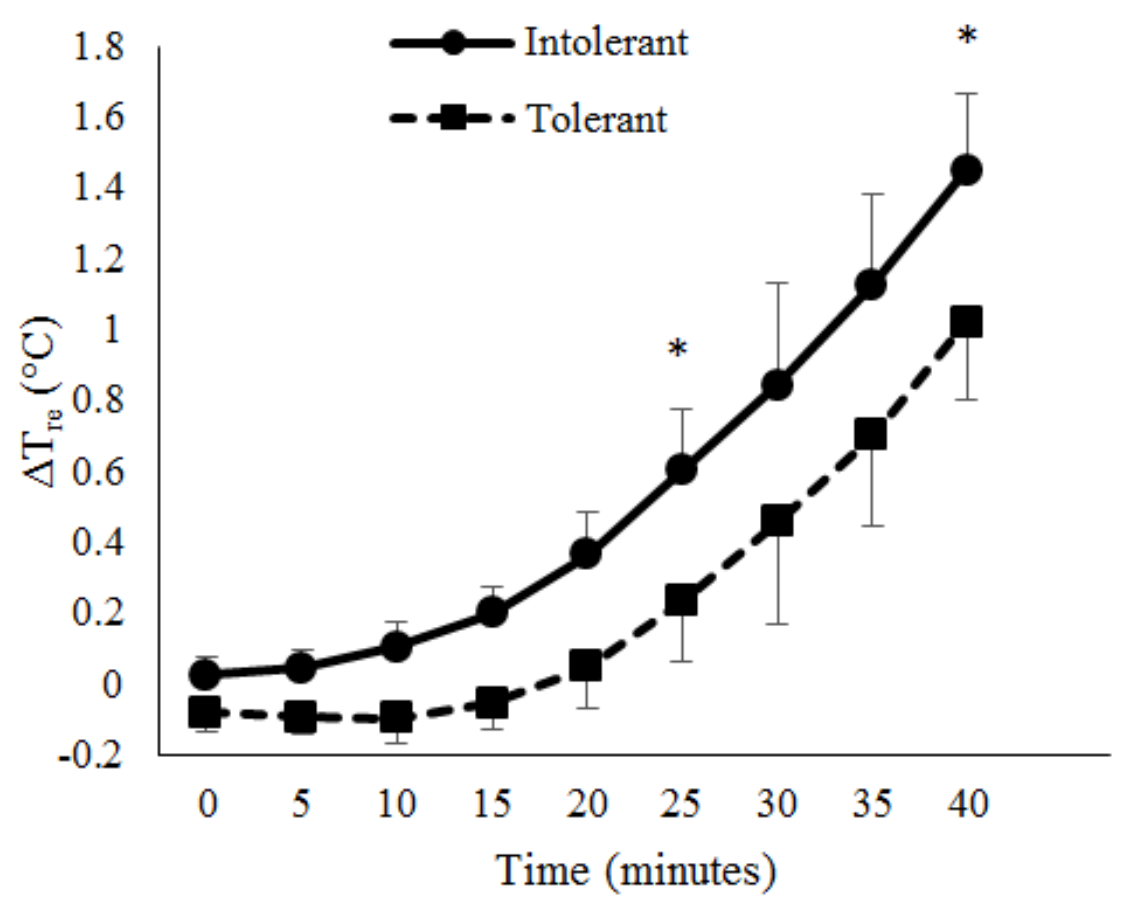



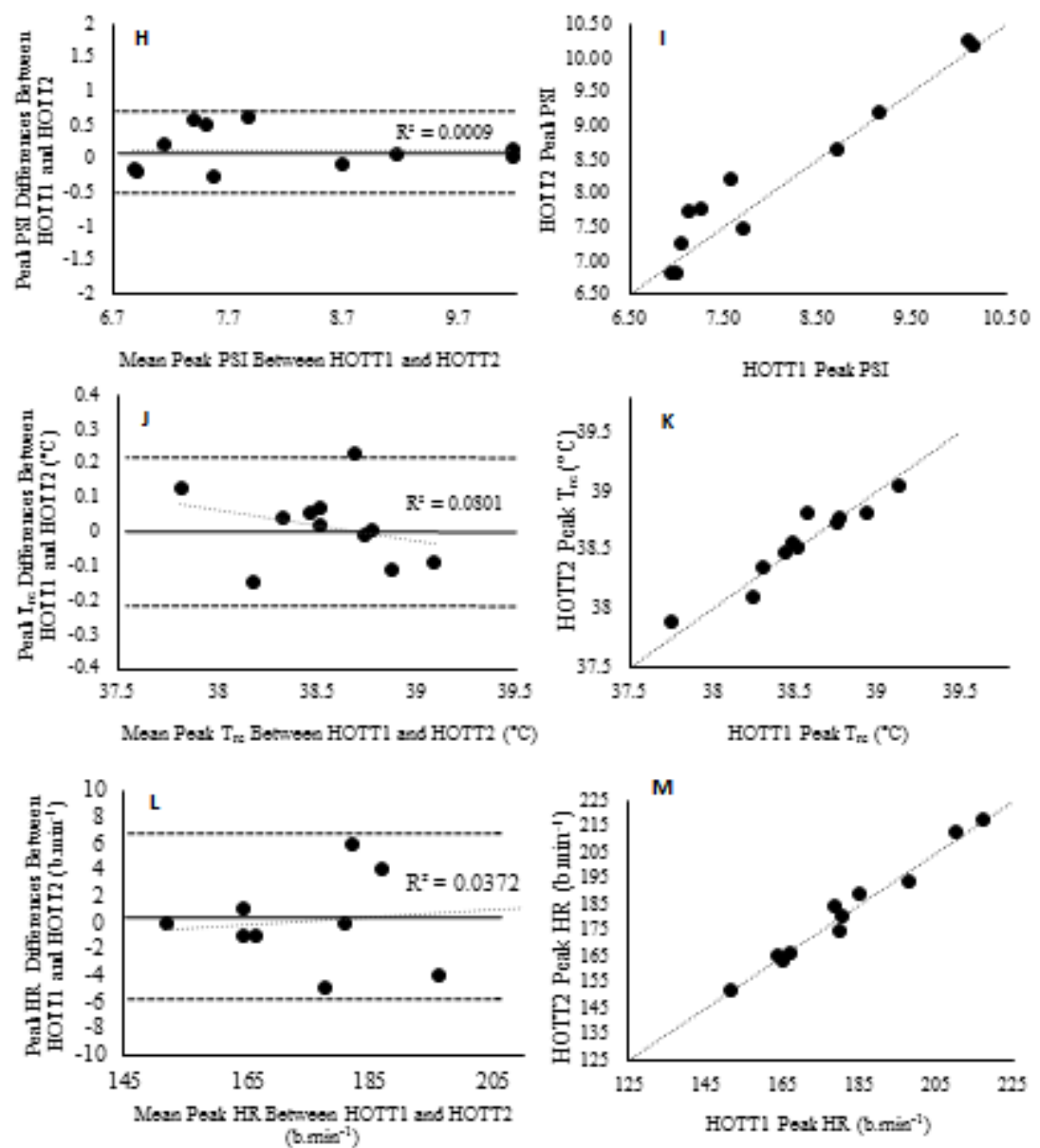


\section{Highlights:}

- A new occupational heat tolerance test (HOTT) set by metabolic heat production.

- HOTT and a standard heat tolerance test produce similar core temperature responses.

- The HOTT is reliable, with no differences in physiological strain between trials.

- The HOTT can identify heat tolerance in a shorter, uncompensable heat strain, test. 